\title{
Persistence of Coordinated Long-Term Potentiation and Dendritic Spine Enlargement at Mature Hippocampal CA1 Synapses Requires N-Cadherin
}

\author{
Ozlem Bozdagi, ${ }^{1 *}$ Xiao-bin Wang, ${ }^{2 *}$ Jessica S. Nikitczuk, ${ }^{1 *}$ Tonya R. Anderson, ${ }^{1}$ Erik B. Bloss, ${ }^{1}$ Glenn L. Radice, ${ }^{3}$ \\ Qiang Zhou, ${ }^{4}$ Deanna L. Benson, ${ }^{1 *}$ and George W. Huntley ${ }^{1 *}$ \\ ${ }^{1}$ Fishberg Department of Neuroscience, Friedman Brain Institute and ${ }^{2}$ Department of Neurology, Mount Sinai School of Medicine, New York, New York \\ 10029, ${ }^{3}$ Center for Translational Medicine, Thomas Jefferson University, Philadelphia, Pennsylvania 19107, and ${ }^{4}$ Genentech, South San Francisco, \\ California 94080
}

Persistent changes in spine shape are coupled to long-lasting synaptic plasticity in hippocampus. The molecules that coordinate such persistent structural and functional plasticity are unknown. Here, we generated mice in which the cell adhesion molecule N-cadherin was conditionally ablated from postnatal, excitatory synapses in hippocampus. We applied to adult mice of either sex a combination of whole-cell recording, two-photon microscopy, and spine morphometric analysis to show that postnatal ablation of N-cadherin has profound effects on the stability of coordinated spine enlargement and long-term potentiation (LTP) at mature CA1 synapses, with no effects on baseline spine density or morphology, baseline properties of synaptic neurotransmission, or long-term depression. Thus, $\mathrm{N}$-cadherin couples persistent spine structural modifications with long-lasting synaptic functional modifications associated selectively with LTP, revealing unexpectedly distinct roles at mature synapses in comparison with earlier, broader functions in synapse and spine development.

\section{Introduction}

Functionally and structurally dynamic synaptic connections enable learning and memory. At young hippocampal synapses, persistent long-term potentiation (LTP) or depression (LTD) is accompanied by increased or decreased spine size, respectively (Matsuzaki et al., 2004; Okamoto et al., 2004; Zhou et al., 2004). While it is clear that sustained alterations in synapse physiology and morphology are coordinately regulated (Kopec et al., 2007; Wang et al., 2008; Yang et al., 2008b), molecular candidates for such a role have not been identified.

Here, we investigate the adhesion molecule $\mathrm{N}$-cadherin as a prime candidate for coordinating synaptic structural and functional plasticity. $\mathrm{N}$-cadherin is the nexus of a transsynaptic, homophilically binding adhesive system that can couple presynaptic and postsynaptic modifications (Yamagata et al., 1995; Fannon and Colman, 1996; Jüngling et al., 2006; Shapiro et al., 2007). The N-cadherin ectodomain binds extracellular motifs in GluA1 or GluA2 subunits (Nuriya and Huganir, 2006; Saglietti et al., 2007), interactions that could

Received March 9, 2010; revised May 21, 2010; accepted June 8, 2010.

This work was supported by National Institutes of Health Grants NS037731, NS050634, MH075783, and F30MH088058. We thank Roxana Mesias, Steven Mortillo, and John Mariani for technical support, and are grateful for the help of William Janssen.

${ }^{*}$ 0.B., X.-b.W., and J.S.N. contributed equally to this work.

${ }^{\ddagger}$ D.L.B. and G.W.H. contributed equally to this work.

Correspondence should be addressed to Deanna L. Benson or George W. Huntley, Fishberg Department of Neuroscience, Box 1065, The Mount Sinai School of Medicine, 1425 Madison Avenue, New York, NY 10029. E-mail: deanna.benson@mssm.edu or george.huntley@mssm.edu.

DOI:10.1523/JNEUROSCI.1223-10.2010

Copyright $\odot 2010$ the authors $\quad 0270-6474 / 10 / 309984-06 \$ 15.00 / 0$ influence postsynaptic currents by regulating surface AMPA receptors (Malinow and Malenka, 2002; Lisman and Raghavachari, 2006; Kerchner and Nicoll, 2008). Additionally, $\mathrm{N}$-cadherin is anchored to F-actin via the catenin proteins, thereby positioned to dynamically regulate spine actin cytoskeleton and to control vesicle pool size (Bamji et al., 2003; Bozdagi et al., 2004; Jüngling et al., 2006). Thus, $\mathrm{N}$-cadherin is well suited to stabilize actin-mediated changes in spine shape in concert with changes in synapse physiology, but this has never been tested.

Using a genetic approach, we show that in the absence of $\mathrm{N}$-cadherin, neither LTP nor spine enlargement persist in adult hippocampus, while $\mathrm{N}$-cadherin is dispensable for LTD. These findings support a model in which $\mathrm{N}$-cadherin couples persistent spine structural modifications with long-lasting synaptic functional modifications associated with LTP of individual, mature synapses, and provide a cellular context for associations found between cadherins and autism and compulsive behaviors (Wang et al., 2009; Dodman et al., 2010).

\section{Materials and Methods}

Conditional knock-out mice. Floxed N-cadherin mice were characterized previously (Kostetskii et al., 2005), backcrossed to a C57BL/6 background (MaxBax, Charles River), then mated to a C57BL/6 $\alpha$ CaMKII-Cre driver line [Camk2a-Cre; T29-1 line; The Jackson Laboratory (Tsien et al., 1996)]. In hippocampus, Cre expression commences by the end of the third postnatal week and includes all excitatory neurons in CA1 by 8 weeks (Tsien et al., 1996; Fukaya et al., 2003; Sonner et al., 2005; Gould et al., 2008). Mice were genotyped by PCR. Treatment and use of all animals conformed to the guidelines established by Mount Sinai's Institutional Animal Care and Use Committee and those of the National Institutes of Health. 
Immunolabeling and immunoblotting. Procedures and controls have been described (Brock et al., 2004). Adult (4-6 months old) conditional knock-out $(\mathrm{cKO})(n=5)$, Cre $(n=4)$, or floxed mice $(n=3)$ were perfused with $4 \%$ paraformaldehyde; hippocampal sections were cut on a vibratome, Nissl stained or immunolabeled for N-cadherin (BD Biosciences), and analyzed by confocal microscopy. Image acquisition parameters were set for controls and held constant.

Postembedding immunogold electron microscopy was according to previous descriptions (Elste and Benson, 2006) using anti-N-cadherin (Tanaka et al., 2000), anti-GluA1 (Millipore), or anti-GluN1 (Siegel et al., 1994) antibodies.

Immunoblots of CA1 lysates were prepared from cKO mice, Cre, or floxed control mice $(n \geq 3)$ as described previously (Brock et al., 2004). In three independent experiments, levels of immunoreactivity were determined by film densitometry (ImageJ) by normalizing N-cadherin band intensity to that of GAPDH within the same lane. Synaptosomes were isolated from a sucrose gradient at the $1.25 / 1 \mathrm{M}$ sucrose interface, and fractions were generated based on 1\% Triton X-100 solubility and pH as described previously (Phillips et al., 2001, 2005). Equal amounts of protein were immunoblotted with anti-N-cadherin or with anti-clathrin (BD Biosciences) to verify fractions.

Whole-cell recording, two-photon image acquisition and analysis. Methods of recording, imaging and analysis were according to our previously published protocols (Zhou et al., 2004; Yang et al., 2008b). All experiments were conducted on CA1 pyramidal cells in acute slices at $32^{\circ} \mathrm{C}$ taken from 2.5- to 6-month-old cKO $(n=5)$, floxed (littermates; $n=4$ ), or Cre $(n=2)$ mice. Neurons were visualized by calcein loading (through the patch pipette) using a two-photon laser scanning system. A baseline of synaptic responses was acquired through a glass pipette positioned $\sim 20 \mu \mathrm{m}$ away from the imaged spines. LTP was induced with a theta burst pairing (TBP) protocol in which two trains of theta-burst stimuli (each train, separated by $20 \mathrm{~s}$, consisted of five bursts at $5 \mathrm{~Hz}$, each burst contained five pulses at $100 \mathrm{~Hz}$ ) were coupled with brief postsynaptic depolarization. Volume analysis of individual spines was performed as detailed previously (Wang et al., 2007; Yang et al., 2008a,b).

Extracellular recording. Methods have been detailed previously (Bozdagi et al., 2008). Acute hippocampal slices were prepared from 3- to 7 -month-old cKO $(n=7)$, littermate or age-matched floxed $(n=5)$, or Cre mice $(n=6)$. All experiments were conducted at $32^{\circ} \mathrm{C}$ on $2-3$ slices per animal. Field EPSPs were recorded from stratum radiatum in CA1, evoked by stimulation of the Schaffer collaterals every $30 \mathrm{~s}$ with $100 \mu \mathrm{s}$ pulses. LTP was induced with theta-burst stimulation (TBS; 10 bursts of four pulses at $100 \mathrm{~Hz}$, with an interval of $200 \mathrm{~ms}$ ) or with a strong, high-frequency tetanic stimulation protocol (HFS, four $1 \mathrm{~s}$ trains of 100 $\mathrm{Hz}$ stimulation, each separated by $5 \mathrm{~min}$ ). LTD was induced by a lowfrequency stimulation (LFS) protocol (900 pulses at $1 \mathrm{~Hz}$ for $15 \mathrm{~min}$ ) (Dudek and Bear, 1992) or by paired-pulse low-frequency stimulation (ppLFS, $1 \mathrm{~Hz}$ for $15 \mathrm{~min}$; $50 \mathrm{~ms}$ interstimulus interval) (Huber et al., 2000).

Spine morphological analysis. Dendritic spine morphology and density were evaluated in intracellularly filled CA1 pyramidal cells using two different protocols. In the first, cells were filled in live hippocampal slices (after whole-cell recording, as above) taken from 2.5- to 3-month-old cKO $(n=4)$ or Cre $(n=3)$ mice. Neurons (12 cKO, 10 Cre, 9-15 dendritic segments per cell) were filled with $0.5 \%$ biocytin and visualized with Alexa-594-streptavidin (Invitrogen). In the second, cells were filled in fixed slices taken from 4 - to 6 -month-old cKO mice $(n=5)$ or floxed mice $(n=2)$ after intracardiac perfusion with $4 \%$ paraformaldehyde. Neurons ( 18 cKO and 8 flox, 9-15 dendritic segments per cell) were filled with 5\% Lucifer yellow as described previously (Radley et al., 2006). Spine morphometric analysis on all cells was then performed by an investigator blind to genotype, using an approach described by Radley et al. (2008). Stacks of confocal images through secondary or tertiary apical dendrites were deconvolved and analyzed using NeuronStudio, an automated program that classifies morphological subtypes of spines (stubby, thin, mushroom) based on spine head-to-neck ratio, spine-head diameter, and other parameters (Wearne et al., 2005; Rodriguez et al., 2006). The detection and classification algorithms were validated in the same dataset by visual inspection of all spines analyzed.
Statistics. All data are presented as mean values \pm SEM. Statistical tests include the Mann-Whitney $U$ test, Student's $t$ test, and ANOVA with Scheffé's post hoc test, each applied where relevant, with $p<0.05$ as a minimum criterion for statistical significance.

\section{Results}

$\mathrm{N}$-cadherin deletion does not alter spine density, morphology, or baseline properties of neurotransmission

We used a Cre-loxP cKO strategy to delete N-cadherin from glutamatergic neurons in hippocampus and other forebrain structures postnatally, circumventing obligatory roles in brain development (Inoue and Sanes, 1997; Jüngling et al., 2006; Kadowaki et al., 2007). These cKO mice ( $\mathrm{Ncad}^{\mathrm{fl} / \mathrm{fl} / \mathrm{Camk} 2 \mathrm{a}-\mathrm{Cre})}$ were compared to a control group in which we combined results from the CaMk2a-Cre (Ncad ${ }^{\text {wt/wt }} /$ CaMk2a-Cre $)$ and flox $\left(\mathrm{Ncad}^{\mathrm{fl} / \mathrm{fl}}\right)$ control lines of mice, since we observed no differences between them in N-cadherin levels, distribution, baseline properties of synaptic transmission, LTP, or capacity for LTP-associated spine enlargement (supplemental Fig. 1, available at www.jneurosci. org as supplemental material).

We first verified that $\mathrm{N}$-cadherin levels were significantly reduced in hippocampus and largely eliminated from synapses in adult cKO mice. Immunoblotting of CA1 lysates showed significantly decreased levels of $\mathrm{N}$-cadherin protein in cKOs in comparison with controls (Fig. $1 A,{ }^{\star} p<0.05$ ). The residual $\mathrm{N}$-cadherin detected in cKO lysates likely corresponds to N-cadherin expressed by glia, GABA neurons, and endothelial cells, all of which do not express Camk2a-Cre (e.g., supplemental Fig. 2, available at www.jneurosci.org as supplemental material). Consistent with this interpretation, N-cadherin levels were near absent from synaptosome and PSD fractions (Fig. $1 B$ ). The loss of N-cadherin from synapses was confirmed by confocal microscopy, which showed a large reduction in immunofluorescent puncta (Fig. $1 C, D)$, and by electron microscopy, which revealed excitatory (asymmetric) synapses with normal-appearing ultrastructure but lacking immunogold particles (Fig. $1 E, F$ ). Quantitative analysis of immunogold-labeled synapses in CA1 verified an $82 \%$ reduction in numbers of $\mathrm{N}$-cadherin-labeled synapses in comparison with controls. Hippocampal cytoarchitecture appeared normal in cKOs as expected (Fig. 1G,H).

$\mathrm{N}$-cadherin regulates spine density and morphology developmentally (Togashi et al., 2002), so we next assessed effects of postnatal N-cadherin ablation on spine density and morphology in adults. Strikingly, there were no significant differences between genotypes in overall spine density (Fig. $1 \mathrm{I}$, J; supplemental Fig. 3, available at www.jneurosci.org as supplemental material), nor in density of thin-, stubby-, or mushroom-spine subtypes (Fig. $1 \mathrm{~K}$; supplemental Fig. 3, available at www.jneurosci.org as supplemental material).

Eliminating N-cadherin in developing neurons also has significant effects on properties of synaptic neurotransmission (Jüngling et al., 2006), so accordingly we analyzed baseline functional properties of mature cKO synapses. Field recordings showed that input-output relationships at Schaffer collateral-CA1 (SC-CA1) synapses were unchanged in $\mathrm{CKO}$ slices in comparison with control slices (supplemental Fig. 4A, available at www.jneurosci.org as supplemental material). In whole-cell recordings, neither paired-pulse facilitation nor the amplitude of mEPSCs were altered in cKO neurons (supplemental Fig. 4B, C, available at www.jneurosci.org as supplemental material). Ultrastructural immunogold localization showed normal distribution of GluA1 and GluN1 at adult cKO synapses (supplemental Fig. 4D, available at www.jneurosci.org as supplemental material). Thus, postnatal deletion of N-cadherin does not 

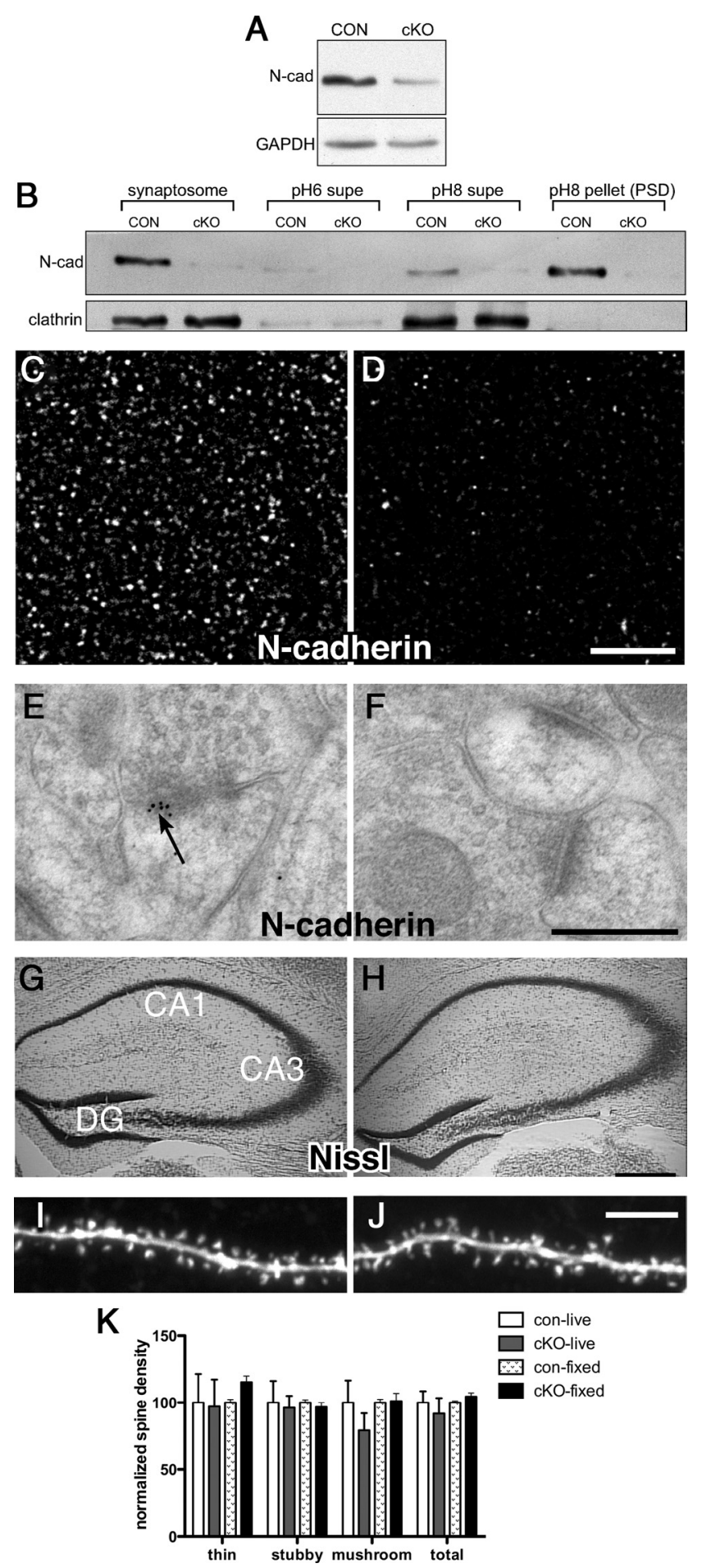

Figure 1. N-cadherin is conditionally deleted from adult CA1 synapses without affecting density or morphology of dendritic spines. $A$, Representative immunoblot of $C A 1$ lysates from $\mathrm{K} K 0$ and control mice. $\boldsymbol{B}$, Synaptosome and Triton-soluble [pH 6 supernatant (supe), containing vesicles and nonsynaptic membrane, and pH 8 supe, enriched with presynaptic matrix and junctional proteins] and -insoluble (pH 8; PSD) fractions. Equal amounts of protein were loaded in each lane and immunolabeled for N-cadherin. $C, D$, Immunofluorescent localization of N-cadherin in control ( $C$ or CKO (D) CA1 stratum radiatum. Representative images were acquired under identical acquisition parameters. Scale bar, $5 \mu \mathrm{m} . \boldsymbol{E}, \boldsymbol{F}$, Postembedding immunogold labeling in CA1 shows localization of $\mathrm{N}$-cadherin at control synapses (arrow, $\boldsymbol{E})$, but an absence of gold labeling at cK0 synapses $(\boldsymbol{F})$. Scale bar, $300 \mathrm{~nm}$. $\boldsymbol{G}, \boldsymbol{H}$, Nissl-staining shows no differences in hippocampal cytoarchitecture between controls $(\boldsymbol{G})$ and cKOs $(\boldsymbol{H})$ as expected. Scale bar, $200 \mu \mathrm{m}$. I, J, Images of spine-bearing apical dendrites of control $(I)$ or CKO $(J)$ CA1 pyramidal neurons filled live in acutely prepared hippocampal slices. Scale bar, $5 \mu \mathrm{m}$. $\boldsymbol{K}$, Quantitative analysis shows no differences between genotypes in overall spine affect basic properties of synaptic neurotransmission at mature $\mathrm{cKO}$ synapses.

$\mathrm{N}$-cadherin is required for persistence of synaptic structural and functional plasticity

We next investigated the contribution of $\mathrm{N}$-cadherin to synaptic and spine modifications in adult cKO and control mice. Previous studies have shown that LTP is accompanied by spine enlargement in young neurons (Matsuzaki et al., 2004). However, it is unknown whether LTP-associated spine structural plasticity occurs in maturity. Thus, we first established that mature control spines are capable of LTP-associated structural modification by simultaneously monitoring spine size and synaptic responses in CA1 neurons before and after applying TBP (Yang et al., 2008b). We found that TBP produced a rapid and persistent increase in spine volume concurrently with an immediate increase in EPSP slope, which gradually reached a plateau by $\sim 30 \mathrm{~min}$, patterns that are similar to those obtained at young synapses (Wang et al., 2008; Yang et al., 2008b) (Fig. $2 A-C$ ). These data demonstrate that mature synapses retain the capacity for coordinated spine/synapse modification with LTP.

However, in the absence of $\mathrm{N}$-cadherin, we found that such coordinated synaptic potentiation and spine expansion were both transient in CA1 neurons (Fig. $2 A-C$ ). Both EPSP slope and spine volume increased immediately to values comparable to those of control synapses/spines, but then both returned gradually to baseline values. Our spine analysis above rules out that such deficits reflect significant differences between genotypes in spine density or morphological subtype. Additionally, for the population of spines that showed expansion, by plotting for each one the TBP-induced expanded volume as a function of its initial volume, we found that the range of initial spine volumes was similar across genotypes, and, regardless of genotype, spines of all initial starting volumes (both small and large) were capable of expansion (data not shown). That both small and large spines can expand is consistent with several previous studies using different LTP induction methods (e.g., chemical, TBP, glutamate uncaging) (Kopec et al., 2007; Steiner et al., 2008; Wang et al., 2008; Yang et al., 2008b), but other studies find only small spines are persistently enlarged (Matsuzaki et al., 2004). These discrepancies likely reflect methodological differences in LTP induction protocols, slice conditions, and age.

We verified the deficits in TBP-LTP seen with whole-cell recordings by using field recordings and a theta burst protocol to induce LTP at SC-CA1 synapses in slices from the same animals (Fig. 2D). These data indicate that the absence of long-lasting LTP in the whole-cell recordings are not due to LTP "rundown" from dialysis. The difference in the time course over which potentiation decrements to baseline is likely attributable to differences between the two protocols in the strength of the stimulation used to induce LTP. It is also possible that $\mathrm{N}$-cadherin deletion simply raises the threshold for LTP. To test this, we induced LTP in adult cKO slices using a strong tetanic stimulation protocol (Frey et al., 1993), but found deficits in persistence of LTP identical to those described for theta burst-LTP (supplemental Fig. 5, available at www.jneurosci.org as supplemental material). Together, these data indicate that at mature CA1

$\leftarrow$

density, nor in density of morphological subtypes (thin, stubby, or mushroom spines). Spine analysis was conducted on cells filled in living slices (live) or in fixed slices (fixed). For each condition, data are normalized to control values (for further analysis, see supplemental Fig. 3, available at www.jneurosci.org). 

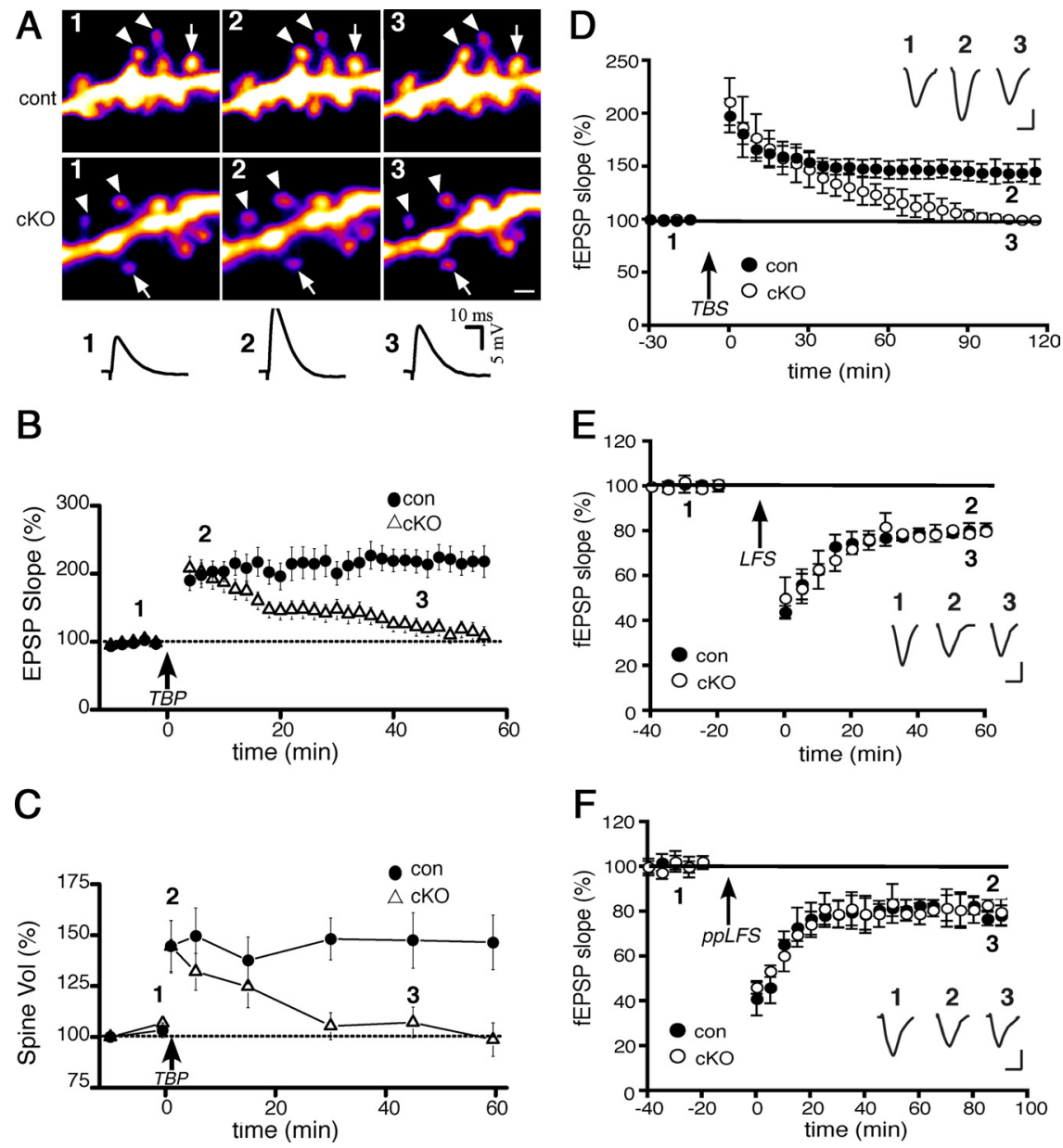

Figure 2. LTP and spine expansion are transient, but LTD is normal, in adult cKO neurons. $A$, Representative images and EPSP traces from single CA1 neurons showing persistent spine expansion with the induction of TBP-LTP in control neurons (top row) but transient expansion (bottom row) and potentiation (traces) in cKO neurons. Expanded and stable spines are marked by arrowheads and arrows, respectively. The spines and EPSP traces are shown before (1), $5 \mathrm{~min}$ after (2), and $45 \mathrm{~min}$ after (3) TBP, and correspond to times shown in the population data ( $\boldsymbol{B}, \boldsymbol{C})$. Scale bar, $1 \mu \mathrm{m}$. $\boldsymbol{B}$, Population data showing EPSPs recorded from the same neurons as in $\mathbf{C}$. TBP (arrow) induces only a transient potentiation in cKO neurons (open) but long-lasting LTP in control neurons. $\boldsymbol{C}$, Population data showing spine enlargement following TBP (arrow) in CKO or control neurons. Initial spine expansion in the cKO neurons is identical to controls, but spine expansion becomes unstable without $\mathrm{N}$-cadherin. Data shown in $\boldsymbol{B}$ and $\boldsymbol{C}$ were collected from a total of 70 spines from 12 cells from 12 slices (cKOs), and a total of 64 spines from 11 cells from 11 slices (controls). $D$, Field recordings of TBS-induced LTP (arrow) in CA1 in acute slices ( $n=12$ cKO slices; 11 control slices) taken from the same cK 0 and control mice shown in $\boldsymbol{A}-\boldsymbol{C}$. Inset, In this and subsequent panels, representative EPSP traces recorded at times indicated. Calibration: $10 \mathrm{~ms}, 0.5 \mathrm{mV}$. $\boldsymbol{E}, \boldsymbol{F}$, Field recordings in CA1 in acute slices from adult $\mathrm{CKO}$ or control mice show no differences between genotypes in two kinds of LTD [LFS, an NMDA receptor-dependent form $(\boldsymbol{E})$, or ppLFS, a metabotropic receptor, protein synthesisdependent form $(\boldsymbol{F})]$.

synapses, $\mathrm{N}$-cadherin is required for persistence, but not induction or initial expression, of LTP and spine enlargement.

\section{LTD does not require $\mathrm{N}$-cadherin}

Studies of cultured hippocampal neurons show that N-cadherin contributes to a chemically elicited LTD-like plasticity (Gorski et al., 2005; Tai et al., 2007). We investigated whether Ncadherin contributes to synaptically elicited LTD of adult SC-CA1 synapses. However, we found no effects of N-cadherin ablation on an NMDA receptor-dependent form of LTD (Dudek and Bear, 1992) (Fig. 2E), nor on a mGluR- and protein synthesis-dependent form of LTD (Huber et al., 2000) (Fig. 2F). Together, the data indicate that at mature hippocampal synapses, $\mathrm{N}$-cadherin contributes selectively to stabilizing NMDA receptor-dependent LTP and concurrent spine enlargement, but is independent of mechanisms that induce or stabilize LTD.

\section{Discussion}

We show here that postnatal ablation of $\mathrm{N}$ cadherin has profound effects on the stability of coordinated spine enlargement and LTP at mature hippocampal synapses, with no effects on baseline spine density or morphology, baseline properties of synaptic neurotransmission, or LTD. Thus, N-cadherin has unexpectedly distinct roles at mature synapses in comparison with earlier, broader functions in synapse and spine development. Further, the data suggest a novel role for $\mathrm{N}$-cadherin in coupling persistent spine structural modifications with longlasting synaptic functional modifications associated with LTP.

Prevailing views of synaptic functions of $\mathrm{N}$-cadherin are dominated by cell culture models that indicate roles in spine morphology (Togashi et al., 2002; Okamura et al., 2004; Elia et al., 2006), spine dynamics and stability (Mysore et al., 2007; Mendez et al., 2010), presynaptic vesicle release (Bozdagi et al., 2004; Jüngling et al., 2006), and LTD (Tai et al., 2007). The approaches used here reveal that these broad developmental roles become restricted at mature synapses to selective contributions to LTP and associated spine structural modification, possibly reflecting the changing intrasynaptic distribution of the $\mathrm{N}$-cadherin-mediated transsynaptic scaffold that occurs as synapses mature (Elste and Benson, 2006).

LTP induction causes an immediate increase in spine size and potentiation followed by a consolidation process that stabilizes such modifications (Matsuzaki et al., 2004; Yang et al., 2008b). We show that $\mathrm{N}$-cadherin is not required for initial plasticity, but subsequently coordinates molecular interactions leading to persistence of LTP and enlarged spine size. A point of molecular convergence in persistence of both forms of plasticity is AMPA receptor subunit trafficking-synaptic incorporation of new subunits is associated with stable LTP (Shi et al., 1999; Park et al., 2004; Yang et al., 2008a) and is necessary for persistent expression of spine expansion (Kopec et al., 2006; Kopec et al., 2007; Yang et al., 2008a). Since N-cadherin interacts with AMPA receptors (Gorski et al., 2005; Nuriya and Huganir, 2006; Saglietti et al., 2007; Silverman et al., 2007), it may be functioning critically here to stabilize or trap receptors within synaptic active zones. Additionally, larger spines associated with LTP have an expanded transsynaptic adhesive interface (Murthy et al., 2001), thus presumably requiring the addition of adhesion molecules that can span and bind tightly across the cleft. Tight adhesion requires cytoskeletal anchoring, and cadherin interactions with F-actin via catenins provide a means for this, and conversely could provide sites for capturing newly generated F-actin polymers (Honkura et al., 2008). Such possibilities are generally consistent with prior studies suggesting that $\mathrm{N}$-cadherin is important for LTP mainte- 
nance (Tang et al., 1998; Bozdagi et al., 2000), and with those showing that $\mathrm{N}$-cadherin in developing neurons may enable changes in spine shape in response to activity (Tanaka et al., 2000; Okamura et al., 2004).

\section{References}

Bamji SX, Shimazu K, Kimes N, Huelsken J, Birchmeier W, Lu B, Reichardt LF (2003) Role of beta-catenin in synaptic vesicle localization and presynaptic assembly. Neuron 40:719-731.

Bozdagi O, Shan W, Tanaka H, Benson DL, Huntley GW (2000) Increasing numbers of synaptic puncta during late-phase LTP: N-cadherin is synthesized, recruited to synaptic sites, and required for potentiation. Neuron 28:245-259.

Bozdagi O, Valcin M, Poskanzer K, Tanaka H, Benson DL (2004) Temporally distinct demands for classic cadherins in synapse formation and maturation. Mol Cell Neurosci 27:509-521.

Bozdagi O, Rich E, Tronel S, Sadahiro M, Patterson K, Shapiro ML, Alberini CM, Huntley GW, Salton SR (2008) The neurotrophininducible gene Vgf regulates hippocampal function and behavior through a brain-derived neurotrophic factor-dependent mechanism. J Neurosci 28:9857-9869.

Brock JH, Elste A, Huntley GW (2004) Distribution and injury-induced plasticity of cadherins in relationship to identified synaptic circuitry in adult rat spinal cord. J Neurosci 24:8806-8817.

Dodman NH, Karlsson EK, Moon-Fanelli A, Galdzicka M, Perloski M, Shuster L, Lindblad-Toh K, Ginns EI (2010) A canine chromosome 7 locus confers compulsive disorder susceptibility. Mol Psychiatry 15:8-10.

Dudek SM, Bear MF (1992) Homosynaptic long-term depression in area CA1 of hippocampus and effects of N-methyl-D-aspartate receptor blockade. Proc Natl Acad Sci U S A 89:4363-4367.

Elia LP, Yamamoto M, Zang K, Reichardt LF (2006) p120 catenin regulates dendritic spine and synapse development through Rho-family GTPases and cadherins. Neuron 51:43-56.

Elste AM, Benson DL (2006) Structural basis for developmentally regulated changes in cadherin function at synapses. J Comp Neurol 495:324-335.

Fannon AM, Colman DR (1996) A model for central synaptic junctional complex formation based on the differential adhesive specificities of the cadherins. Neuron 17:423-434.

Frey U, Huang YY, Kandel ER (1993) Effects of cAMP simulate a late stage of LTP in hippocampal CA1 neuron. Science 260:1661-1664.

Fukaya M, Kato A, Lovett C, Tonegawa S, Watanabe M (2003) Retention of NMDA receptor NR2 subunits in the lumen of endoplasmic reticulum in targeted NR1 knockout mice. Proc Natl Acad Sci U S A 100:4855-4860.

Gorski JA, Gomez LL, Scott JD, Dell'Acqua ML (2005) Association of an A-kinase-anchoring protein signaling scaffold with cadherin adhesion molecules in neurons and epithelial cells. Mol Biol Cell 16:3574-3590.

Gould TD, O'Donnell KC, Picchini AM, Dow ER, Chen G, Manji HK (2008) Generation and behavioral characterization of beta-catenin forebrainspecific conditional knock-out mice. Behav Brain Res 189:117-125.

Honkura N, Matsuzaki M, Noguchi J, Ellis-Davies GC, Kasai H (2008) The subspine organization of actin fibers regulates the structure and plasticity of dendritic spines. Neuron 57:719-729.

Huber KM, Kayser MS, Bear MF (2000) Role for rapid dendritic protein synthesis in hippocampal mGluR-dependent long-term depression. Science 288:1254-1257.

Inoue A, Sanes JR (1997) Lamina-specific connectivity in the brain: regulation by $\mathrm{N}$-cadherin, neurotrophins, and glycoconjugates. Science 276:1428-1431.

Jüngling K, Eulenburg V, Moore R, Kemler R, Lessmann V, Gottmann K (2006) N-cadherin transsynaptically regulates short-term plasticity at glutamatergic synapses in embryonic stem cell-derived neurons. J Neurosci 26:6968-6978.

Kadowaki M, Nakamura S, Machon O, Krauss S, Radice GL, Takeichi M (2007) N-cadherin mediates cortical organization in the mouse brain. Dev Biol 304:22-33.

Kerchner GA, Nicoll RA (2008) Silent synapses and the emergence of a postsynaptic mechanism for LTP. Nat Rev Neurosci 9:813-825.

Kopec CD, Li B, Wei W, Boehm J, Malinow R (2006) Glutamate receptor exocytosis and spine enlargement during chemically induced long-term potentiation. J Neurosci 26:2000-2009.

Kopec CD, Real E, Kessels HW, Malinow R (2007) GluR1 links structural and functional plasticity at excitatory synapses. J Neurosci 27:13706-13718.

Kostetskii I, Li J, Xiong Y, Zhou R, Ferrari VA, Patel VV, Molkentin JD, Radice GL (2005) Induced deletion of the N-cadherin gene in the heart leads to dissolution of the intercalated disc structure. Circ Res 96:346-354.

Lisman J, Raghavachari S (2006) A unified model of the presynaptic and postsynaptic changes during LTP at CA1 synapses. Sci STKE 2006:re11.

Malinow R, Malenka RC (2002) AMPA receptor trafficking and synaptic plasticity. Annu Rev Neurosci 25:103-126.

Matsuzaki M, Honkura N, Ellis-Davies GC, Kasai H (2004) Structural basis of long-term potentiation in single dendritic spines. Nature 429:761-766.

Mendez P, De Roo M, Poglia L, Klauser P, Muller D (2010) N-cadherin mediates plasticity-induced long-term spine stabilization. J Cell Biol 189:589-600.

Murthy VN, Schikorski T, Stevens CF, Zhu Y (2001) Inactivity produces increases in neurotransmitter release and synapse size. Neuron 32: 673-682.

Mysore SP, Tai CY, Schuman EM (2007) Effects of N-cadherin disruption on spine morphological dynamics. Front Cell Neurosci 1:1-14.

Nuriya M, Huganir RL (2006) Regulation of AMPA receptor trafficking by N-cadherin. J Neurochem 97:652-661.

Okamoto K, Nagai T, Miyawaki A, Hayashi Y (2004) Rapid and persistent modulation of actin dynamics regulates postsynaptic reorganization underlying bidirectional plasticity. Nat Neurosci 7:1104-1112.

Okamura K, Tanaka H, Yagita Y, Saeki Y, Taguchi A, Hiraoka Y, Zeng LH, Colman DR, Miki N (2004) Cadherin activity is required for activityinduced spine remodeling. J Cell Biol 167:961-972.

Park M, Penick EC, Edwards JG, Kauer JA, Ehlers MD (2004) Recycling endosomes supply AMPA receptors for LTP. Science 305:1972-1975.

Phillips GR, Huang JK, Wang Y, Tanaka H, Shapiro L, Zhang W, Shan WS, Arndt K, Frank M, Gordon RE, Gawinowicz MA, Zhao Y, Colman DR (2001) The presynaptic particle web. ultrastructure, composition, dissolution, and reconstitution. Neuron 32:63-77.

Phillips GR, Florens L, Tanaka H, Khaing ZZ, Fidler L, Yates JR 3rd, Colman DR (2005) Proteomic comparison of two fractions derived from the transsynaptic scaffold. J Neurosci Res 81:762-775.

Radley JJ, Rocher AB, Miller M, Janssen WG, Liston C, Hof PR, McEwen BS, Morrison JH (2006) Repeated stress induces dendritic spine loss in the rat medial prefrontal cortex. Cereb Cortex 16:313-320.

Radley JJ, Rocher AB, Rodriguez A, Ehlenberger DB, Dammann M, McEwen BS, Morrison JH, Wearne SL, Hof PR (2008) Repeated stress alters dendritic spine morphology in the rat medial prefrontal cortex. J Comp Neurol 507:1141-1150.

Rodriguez A, Ehlenberger DB, Hof PR, Wearne SL (2006) Rayburst sampling, an algorithm for automated three-dimensional shape analysis from laser scanning microscopy images. Nat Protoc 1:2152-2161.

Saglietti L, Dequidt C, Kamieniarz K, Rousset MC, Valnegri P, Thoumine O, Beretta F, Fagni L, Choquet D, Sala C, Sheng M, Passafaro M (2007) Extracellular interactions between GluR2 and N-cadherin in spine regulation. Neuron 54:461-477.

Shapiro L, Love J, Colman DR (2007) Adhesion molecules in the nervous system: structural insights into function and diversity. Annu Rev Neurosci 30:451-474.

Shi SH, Hayashi Y, Petralia RS, Zaman SH, Wenthold RJ, Svoboda K, Malinow R (1999) Rapid spine delivery and redistribution of AMPA receptors after synaptic NMDA receptor activation. Science 284:1811-1816.

Siegel SJ, Brose N, Janssen WG, Gasic GP, Jahn R, Heinemann SF, Morrison JH (1994) Regional, cellular, and ultrastructural distribution of N-methyl-D-aspartate receptor subunit 1 in monkey hippocampus. Proc Natl Acad Sci U S A 91:564-568.

Silverman JB, Restituito S, Lu W, Lee-Edwards L, Khatri L, Ziff EB (2007) Synaptic anchorage of AMPA receptors by cadherins through neural plakophilin-related arm protein AMPA receptor-binding protein complexes. J Neurosci 27:8505-8516.

Sonner JM, Cascio M, Xing Y, Fanselow MS, Kralic JE, Morrow AL, Korpi ER, Hardy S, Sloat B, Eger EI 2nd, Homanics GE (2005) Alpha 1 subunitcontaining GABA type A receptors in forebrain contribute to the effect of inhaled anesthetics on conditioned fear. Mol Pharmacol 68:61-68.

Steiner P, Higley MJ, Xu W, Czervionke BL, Malenka RC, Sabatini BL (2008) Destabilization of the postsynaptic density by PSD-95 serine 73 phos- 
phorylation inhibits spine growth and synaptic plasticity. Neuron 60:788-802.

Tai CY, Mysore SP, Chiu C, Schuman EM (2007) Activity-regulated N-cadherin endocytosis. Neuron 54:771-785.

Tanaka H, Shan W, Phillips GR, Arndt K, Bozdagi O, Shapiro L, Huntley GW, Benson DL, Colman DR (2000) Molecular modification of N-cadherin in response to synaptic activity. Neuron 25:93-107.

Tang L, Hung CP, Schuman EM (1998) A role for the cadherin family of cell adhesion molecules in hippocampal long-term potentiation. Neuron 20:1165-1175.

Togashi H, Abe K, Mizoguchi A, Takaoka K, Chisaka O, Takeichi M (2002) Cadherin regulates dendritic spine morphogenesis. Neuron 35:77-89.

Tsien JZ, Chen DF, Gerber D, Tom C, Mercer EH, Anderson DJ, Mayford M, Kandel ER, Tonegawa S (1996) Subregion- and cell type-restricted gene knockout in mouse brain. Cell 87:1317-1326.

Wang K, Zhang H, Ma D, Bucan M, Glessner JT, Abrahams BS, Salyakina D, Imielinski M, Bradfield JP, Sleiman PM, Kim CE, Hou C, Frackelton E, Chiavacci R, Takahashi N, Sakurai T, Rappaport E, Lajonchere CM, Munson J, Estes A, et al. (2009) Common genetic variants on 5p14.1 associate with autism spectrum disorders. Nature 459:528-533.

Wang XB, Yang Y, Zhou Q (2007) Independent expression of synaptic and morphological plasticity associated with long-term depression. J Neurosci 27:12419-12429.

Wang XB, Bozdagi O, Nikitczuk JS, Zhai ZW, Zhou Q, Huntley GW (2008) Extracellular proteolysis by matrix metalloproteinase- 9 drives dendritic spine enlargement and long-term potentiation coordinately. Proc Natl Acad Sci U S A 105:19520-19525.

Wearne SL, Rodriguez A, Ehlenberger DB, Rocher AB, Henderson SC, Hof PR (2005) New techniques for imaging, digitization and analysis of three-dimensional neural morphology on multiple scales. Neuroscience 136:661-680.

Yamagata M, Herman JP, Sanes JR (1995) Lamina-specific expression of adhesion molecules in developing chick optic tectum. J Neurosci 15:4556-4571.

Yang Y, Wang XB, Frerking M, Zhou Q (2008a) Delivery of AMPA receptors to perisynaptic sites precedes the full expression of long-term potentiation. Proc Natl Acad Sci U S A 105:11388-11393.

Yang Y, Wang XB, Frerking M, Zhou Q (2008b) Spine expansion and stabilization associated with long-term potentiation. J Neurosci 28:57405751.

Zhou Q, Homma KJ, Poo MM (2004) Shrinkage of dendritic spines associated with long-term depression of hippocampal synapses. Neuron 44: $749-757$. 